\title{
A Saint Louis encephalitis and Rocio virus serosurvey in Brazilian horses
}

\author{
Jaqueline Raymondi Silva ${ }^{[1]}$, Marilia Farignoli Romeiro ${ }^{[1]}$, William Marciel de Souza ${ }^{[1]}$, \\ Thiago Demarchi Munhoz ${ }^{[2]}$, Gustavo Puía Borges ${ }^{[3]}$, Otavio Augusto Brioschi Soares ${ }^{[4]}$, \\ Carlos Henrique Coelho de Campos ${ }^{[4]}$, Rosângela Zacarias Machado ${ }^{[2]}$, \\ Maria Luana Cristiny Rodrigues Silva ${ }^{[5]}$, Joice Lara Maia Faria ${ }^{[6]}$, \\ Juliana Helena Chávez ${ }^{[1]}$ and Luiz Tadeu Moraes Figueiredo ${ }^{[1]}$
}

[1]. Centro de Pesquisa em Virologia, Faculdade de Medicina de Ribeirão Preto, Universidade de São Paulo, Ribeirão Preto, SP. [2]. Faculdade de Ciências Agrárias e Veterinárias, Universidade Estadual Paulista, Jaboticabal, SP. [3]. Escola de Ciências Veterinárias, Universidade Federal do Mato Grosso do Sul, Campo Grande, MS. [4]. Academia Militar Agulhas Negras, Resende, Rio de Janeiro, RJ. [5]. Unidade Acadêmica de Medicina Veterinária, Universidade Federal de Campina Grande, Campina Grande, PB. [6]. Faculdade de Medicina Veterinária, Universidade de Uberaba, Uberaba, MG.

\begin{abstract}
Introduction: Arboviruses are an important public health problem in Brazil, in especially flaviviruses, including the Saint Louis encephalitis virus (SLEV) and the Rocio virus (ROCV), are especially problematic. These viruses are transmitted to humans or other vertebrates through arthropod bites and may cause diseases with clinical manifestations that range from asymptomatic infection, viral hemorrhagic fever to encephalitis. Methods: A serological survey of horses from various regions of Brazil using an enzyme-linked immunosorbent assay (ELISA) with recombinant SLEV domain III peptides and ROCV E protein as antigens. Results: Overall, 415 (55.1\%) of the 753 horses that were screened were seropositive for flavivirus and, among them, monotypic reactions were observed to SLEV in $93(12.3 \%)$ and to ROCV in $46(6.1 \%)$. These results suggested that these viruses, or other closely related viruses, are infecting horses in Brazil. However, none of the studied horses presented central nervous system infection symptoms. Conclusions: Our results suggest that SLEV and ROCV previously circulated among horses in northeast, west-central and southeast Brazil.
\end{abstract}

Keywords: Arbovirus. Saint Louis encephalitis virus. Rocio virus. Serosurvey. Epidemiology. Brazil.

\section{INTRODUCTION}

Arboviruses are transmitted to humans or other vertebrates through hematophagous arthropod bites ${ }^{1}$. The emergence or reemergence of arboviruses is a natural phenomenon associated with species evolution and adaptation. Brazil is a large tropical country $\left(8,514,215 \mathrm{~km}^{2}\right)$ with more than one-third of its territory still covered by rainforests and other natural ecosystems; it also has an extremely diverse flora and fauna ${ }^{2}$. Additionally, Brazil has a population of approximately 200 million people, most of whom live in large cities in the northeast and southeast regions of the country. These conditions are ideal for the existence of many arboviruses, which are maintained in a large variety of zoonotic cycles. In fact, more than 200 distinct arbovirus species

\footnotetext{
Address to: Dr. Luiz Tadeu Moraes Figueiredo. Centro de Pesquisa em Virologia/ FMRP/USP. Av. Bandeirantes 3900, 14049-900 Ribeirão Preto, SP, Brasil.

Phone: 5516 3602-4580; Fax: 55 16 3602-3376

e-mail: 1tmfigue@fmrp.usp.br; wmarciel@hotmail.com

Received 31 May 2014

Accepted 4 August 2014
}

have been isolated in Brazil, and approximately 40 of them cause human diseases ${ }^{3}$.

The genus Flavivirus, family Flaviviridae, comprises positive-sense, single-stranded ribonucleic acid (RNA) viruses and includes some of the most important arboviral pathogens. In South America, Saint Louis encephalitis virus (SLEV) and Rocio virus (ROCV), which are both flaviviruses that are closely related to the Japanese encephalitis serocomplex viruses, can produce human encephalitis ${ }^{4,5}$. ROCV was first isolated from a fatal human case during an epidemic of encephalitis in Ribeira Valley in the southeastern region of the State of São Paulo, Brazil, in $1975^{6}$. This ROCV epidemic involved over 1,000 reported cases with a $10 \%$ fatality rate and sequelae in $20 \%$ of the cases ${ }^{2}$.

SLEV was first isolated in 1933 during a major epidemic in St Louis, Missouri, USA. The virus is widely distributed throughout the western hemisphere from Canada to Argentina and outbreaks or clusters of encephalitis cases associated with SLEV have been reported with fatality rates that range from $5 \%$ to $20 \%{ }^{7,8}$. In Brazil, SLEV infections have been diagnosed during acute febrile illness or in meningoencephalitis patients, with 2 patients from State of Pará in the northern region of Brazil and 9 patients from State of São Paulo in the southeastern region exhibiting these symptoms ${ }^{9-12}$. 
Additionally, SLEV was recently isolated from the brain of a horse that presented neurological signs in the countryside of State of Minas Gerais, Brazil ${ }^{13}$. Moreover, serological evidence of ROCV circulation in horses was recently reported in the Pantanal, Brazil ${ }^{14}$. Consequently, these large animals are suitable sources for serological studies of flaviviruses that can cause encephalitis. Here, we report a serological survey of horses from various regions of Brazil for SLEV and/or ROCV detection.

\section{METHODS}

\section{Samples}

Serum samples were collected from 753 horses from 2004 through 2009 in 5 Brazilian states, which included 183 serum samples collected at Faculdade de Ciências Agrárias e Veterinárias da Universidade Estadual Paulista, Jaboticabal, State of São Paulo; 15 serum samples collected at Universidade de Uberaba, Uberaba, Minas Gerais; 267 serum samples collected through an epidemiological surveillance in Mato Grosso do Sul; 200 serum samples collected from horses at the Military Academy of the Black Needles in Resende, Rio de Janeiro; and 88 serum samples collected at Universidade Federal de Campina Grande, in Campina Grande, Paraíba. All participant horses were healthy at the time of blood collection and had no history of central nervous system infections or of vaccinations against flaviviruses.

\section{ELISA}

Serum samples were tested in duplicate using an indirect immunoglobulin $\mathrm{G}$ ( $\mathrm{IgG}$ ) enzyme-linked immunosorbent assay (ELISA) with domain III (rDIII) from SLEV and ROCV in Escherichia coli. Briefly, high-binding affinity 96-well microtiter plates (Corning, USA) were coated with 300ng of rDIII antigen and incubated for $48 \mathrm{~h}$ at $4^{\circ} \mathrm{C}$. Blocking was performed by incubating the plates for $2 \mathrm{~h}$ at $37^{\circ} \mathrm{C}$ with $10 \%$ nonfat milk in PBS. SLEV and ROCV mouse immune ascitic fluid (MIAF) were used as positive controls. The MIAFs were incubated at $37^{\circ} \mathrm{C}$ for $1 \mathrm{~h}$. An anti-mouse IgG conjugated with peroxidase (Sigma, USA) was used as the secondary antibody. The reaction was quantified by adding 2,2-azinobis (3-ethylbenzthiazolinesulfonic acid) (ABTS) (KPL, USA) after a 30 minute incubation at $37^{\circ} \mathrm{C}$. Spectrophotometry was performed at $405 \mathrm{~nm}$ using a Multiskan Spectrum (Thermo, USA) $)^{15,16}$. The test cut-off value was determined using optical density (OD) means added to three times the standard deviations of ODs obtained from at least four negative-control sera. After the test, all positive samples were diluted 100- to 1,600-fold and tested using ELISA to determine serum titers.

\section{Ethical considerations}

The sample collection and handling procedures were approved by the University of São Paulo Animal Ethics Committee, Brazil (protocol \# 161-2008).

\section{RESULTS}

A total of $415(55.1 \%)$ of the 753 equine sera had $\mathrm{IgG}$ antibodies to SLEV and ROCV. Additionally, 271 (35.9\%) sera reacted to SLEV and $144(19.1 \%)$ to ROCV. When considering only the monotypic reactions, $93(12.3 \%)$ serum samples had antibodies to SLEV and $46(6.1 \%)$ to ROCV. The monotypic positive serum titers ranged from 100 to 800 in the horses from the States of Rio de Janeiro, Mato Grosso do Sul and Paraíba, with the exception of one serum sample from Mato Grosso do Sul state, which had a titer of 1,600. An elevated seropositivity to SLEV was found in State of Mato Grosso do Sul, which had $140(52.4 \%)$ positive samples, and an elevated seropositivity to ROCV was found in State of Paraíba, which had 31 (35.2\%) positive samples, as shown in Table $\mathbf{1 .}$

\section{DISCUSSION}

Our results indicate that SLEV, ROCV or a very closely related virus from the Japanese encephalitis serocomplex had infected horses in Brazil. SLEV has been isolated from Culex declarator and Culex coronator $^{17}$. Presumably,

TABLE 1 - Positive SLEV and ROCV samples according to the rDIII ELISA.

\begin{tabular}{|c|c|c|c|c|c|c|c|c|c|}
\hline \multirow[b]{3}{*}{ Brazilian States } & \multirow[b]{3}{*}{ Samples } & \multicolumn{4}{|c|}{ Rocio } & \multicolumn{4}{|c|}{ Saint Louis encephalitis } \\
\hline & & \multicolumn{2}{|c|}{ total } & \multicolumn{2}{|c|}{ monotypic } & \multicolumn{2}{|c|}{ total } & \multicolumn{2}{|c|}{ monotypic } \\
\hline & & $\mathrm{n}$ & $\%$ & $\mathrm{n}$ & $\%$ & $\mathrm{n}$ & $\%$ & $\mathrm{n}$ & $\%$ \\
\hline Mato Grosso do Sul & 267 & 63 & 23.5 & 13 & 4.9 & 140 & 52.4 & 56 & 21.0 \\
\hline Minas Gerais & 15 & 0 & 0.0 & 0 & 0.0 & 3 & 20.0 & 3 & 20.0 \\
\hline Rio de Janeiro & 200 & 34 & 17.0 & 13 & 6.5 & 41 & 20.5 & 12 & 6.0 \\
\hline São Paulo & 183 & 16 & 8.7 & 8 & 4.4 & 55 & 30.0 & 18 & 9.8 \\
\hline Total & 753 & 144 & 19.1 & 46 & 6.1 & 271 & 35.9 & 93 & 12.3 \\
\hline
\end{tabular}

SLEV: Saint Louis encephalitis virus; ROCV: Rocio virus; rDIII: domain III; ELISA: enzyme-linked immunosorbent assay. 
a Culex species that serves as a competent vector for these viruses also feeds on horses and is responsible for their infection. Wild birds, monkeys, sloths, armadillos and marsupials could act as amplifier vertebrate hosts in Brazil ${ }^{18}$. SLEV also infects humans and can lead to acute febrile illness and meningoencephalitis ${ }^{10}$. ROCV, a flavivirus that was only detected in the southeastern region of Brazil, produced an outbreak in the 1970s that involved hundreds of encephalitis cases. ROCV was also isolated from a wild bird, Zonotrichia capensis, and wild birds are considered to be amplifier vertebrate hosts of this virus. Additionally, ROCV was also isolated from the mosquito species Psorophora ferox, and Aedes scapularis is likely another mosquito species involved in ROCV transmission ${ }^{19,20}$. The factors responsible for the appearance and disappearance of this virus are unknown.

Many (55\%) of the horses studied were seropositive for ROCV and/or SLEV. Moreover, 93 (12.3\%) of the horses presented monotypic reactions to SLEV, and 46 (6.1\%) presented monotypic reactions to ROCV. These seropositivity levels are high, indicating that flaviviruses may circulate widely in Brazil ${ }^{14,21}$. We also show the first evidence of widespread ROCV infection among horses in Brazil. Horses are large domestic animals that live outside the protection of buildings and are therefore common mosquito bite victims. Consequently, these animals are a suitable source for sero-epidemiological studies on mosquito-borne viruses.

Most $(82 \%)$ of the horse serum samples studied here were positive for both viruses, suggesting a tendency toward cross-reactions among flaviviruses that circulate in Brazil (Bussuquara, Cacipacore, Iguape, Ilheus, yellow fever, West Nile and dengue 1, 2, 3 and 4 viruses) and precluding a discrimination of the infecting virus. Another possibility is that the animals were infected by multiple flaviviruses during their lifetimes ${ }^{3,22}$; however, $18 \%$ of the serum samples showed monotypic reactions in titers, suggesting that a subset of the horses were infected by either SLEV (12.3\%) or ROCV (6.1\%).

The highest monotypic positivity to SLEV was found in the horse serum samples from the States of Mato Grosso do Sul (20\%) and Minas Gerais (20\%), suggesting that higher circulating levels of the viruses might be found in the southeastern and central-western regions of Brazil. However, we have not analyzed horses from the southern and northern regions. The highest monotypic positivity to ROCV was found in the horse serum samples from State of Paraíba (13.6\%), in the northeastern region. However, these higher rates of seropositivity were not significantly different from those observed in other Brazilian states.

Our results demonstrate that the indirect IgG-ELISA, which evaluated the SLEV and ROCV rDIII antigen, is suitable to screen a large amount of sera and could therefore be used during serological Flavivirus surveys ${ }^{15}$. Unfortunately, due to the low volume of each serum sample, it was not possible to perform neutralization tests on the ELISA-positive sera to confirm the infections by SLEV and ROCV.

It is possible that SLEV and ROCV have been circulating quietly throughout Brazil, most likely in cycles that involve migratory birds and mosquitoes (Culex spp. and Psorophora spp.) $)^{3,13,19}$.
However, the serological evidence presented here, together with the lack of epizootic reports in horses, suggests the presence of asymptomatic, subclinical or pathognomonic infections in these animals. Interestingly, SLEV circulation may have coincided with human outbreaks of dengue-like diseases in São José do Rio Preto ${ }^{9-10}$ and with outbreaks in horses from Minas Gerais state $^{13}$. Furthermore, a case was reported recently in Ribeirão Preto City, São Paulo ${ }^{23}$. However, other outbreaks of ROCV and SLEV may be occurring without being detected.

In conclusion, here, we report serological evidence of SLEV and ROCV infections in horses and the possible cocirculation of other flaviviruses. The data presented here are particularly important because many non-dengue acute febrile illnesses remain undiagnosed in Brazil. This report should serve as a warning to the Brazilian public health authorities that routine diagnoses of other (non-dengue) flaviviruses should be implemented and that surveillance should also be increased, particularly for SLEV and ROCV.

\section{CONFLICT OF INTEREST}

The authors declare that there is no conflict of interest.

\section{FINANCIAL SUPPORT}

This work was supported by FAPESP - Fundação de Amparo à Pesquisa do Estado de São Paulo (Grant Number: 08/506176 and Scholarships Numbers: 08/52685-9; 12/02836-6 and 12/24150-9), Brazil.

\section{REFERENCES}

1. Turtle L, Griffiths MJ, Solomon T. Encephalitis caused by flaviviruses. QJM 2012; 105:219-223.

2. Figueiredo LT. Emergent arboviruses in Brazil. Rev Soc Bras Med Trop 2007; 40:224-229.

3. Vasconcelos PF, Travassos da Rosa AP, Rodrigues SG, Travassos da Rosa ES, Dégallier N, Travassos da Rosa JF. Inadequate management of natural ecosystem in the Brazilian Amazon region results in the emergence and reemergence of arboviruses. Cad Saude Publica 2001; 17 (supl):155-164.

4. Medeiros DB, Nunes MR, Vasconcelos PF, Chang GJ, Kuno G. Complete genome characterization of Rocio virus (Flavivirus: Flaviviridae), a Brazilian flavivirus isolated from a fatal case of encephalitis during an epidemic in Sao Paulo state. J Gen Virol 2007; 88:2237-2246.

5. Rodrigues SG, Nunes MR, Casseb SM, Prazeres AS, Rodrigues DS, Silva MO, et al. Molecular epidemiology of Saint Louis encephalitis virus in the Brazilian Amazon: genetic divergence and dispersal. J Gen Virol 2010; 91:2420-2427.

6. Iversson LB, Travassos da Rosa AP, Rosa MD. Recent occurrence of human infection by Rocio arbovirus in the Valley of Ribeira region. Rev Inst Med Trop Sao Paulo 1989; 31:28-31.

7. Reisen WK. Epidemiology of St. Louis encephalitis virus. Adv Virus Res 2003; 61:139-83.

8. Tsai TF, Mitchell CJ. St. Louis encephalitis. In: Monath TP, editor. The arboviruses: epidemiology and ecology. Boca Raton, FL: CRC Press; 1988. p. 431-458. 
9. Mondini A, Bronzoni RV, Cardeal IL, dos Santos TM, Lázaro E, Nunes SH, et al.. Simultaneous infection by DENV-3 and SLEV in Brazil. J Clin Virol 2007; 40:84-86.

10. Mondini A, Cardeal IL, Lázaro E, Nunes SH, Moreira CC, Rahal P, et al. Saint Louis encephalitis virus, Brazil. Emerg Infect Dis 2007; 13:176-178

11. Pinheiro FP, LeDuc JW, Travassos da Rosa AP, Leite OF. Isolation of St. Louis encephalitis virus from a patient in Belém, Brazil. Am J Trop Med Hyg 1981; 30:145-148.

12. Rocco IM, Santos CL, Bisordi I, Petrella SM, Pereira LE, Souza RP, et al. St. Louis encephalitis virus: first isolation from a human in São Paulo State, Brazil. Rev Inst Med Trop Sao Paulo 2005; 47:281-285.

13. Rosa R, Costa EA, Marques RE, Oliveira TS, Furtini R, Bomfim MR, et al. Isolation of Saint louis encephalitis virus from a horse with neurological disease in Brazil. PLoS Negl Trop Dis 2013; 7:e2537.

14. Pauvolid-Corrêa A, Campos Z, Juliano R, Velez J, Nogueira RM, Komar N. Serological evidence of widespread circulation of West Nile virus and other flaviviruses in equines of the Pantanal, Brazil. PLoS Negl Trop Dis 2014; 8:e2706.

15. Chávez JH, Silva JR, Amarilla AA, Moraes Figueiredo LT. Domain III peptides from flavivirus envelope protein are useful antigens for serologic diagnosis and targets for immunization. Biologicals 2010; 38:613-618.

16. Chávez JH, Reis VP, Silva JR, Laure HJ, Rosa JC, Fonseca BA, et al. Production and diagnostic application of recombinant domain III of West Nile envelope protein in Brazil. Rev Soc Bras Med Trop 2013; 46:97-99.
17. Vasconcelos PFC, Travassos da Rosa APA, Pinheiro FP, Shope RE, Travassos da Rosa JFS, Rodrigues SG, et al. Arboviruses pathogenic for man in Brazil. In: Travassos da Rosa APA, Vasconcelos PFC, Travassos da Rosa JFS, editors. An overview of Arbovirology in Brazil and Neighbouring Countries. Instituto Evandro Chagas, Belém. 1998. p. 72-99.

18. Figueiredo LT. The Brazilian flaviviruses. Microbes Infect 2000; 2:1643-1649

19. de Souza Lopes O, de Abreu Sacchetta L, Francy DB, Jakob WL, Calisher $\mathrm{CH}$. Emergence of a new arbovirus disease in Brazil. III. Isolation of Rocio virus from Psorophora Ferox (Humboldt, 1819). Am J Epidemiol 1981; 113:122-125.

20. Mitchell CJ, Forattini OP, Miller BR. Vector competence experiments with Rocio virus and three mosquito species from the epidemic zone in Brazil. Rev Saude Publica 1986; 20:171-177.

21. Pauvolid-Corrêa A, Tavares FN, Costa EV, Burlandy FM, Murta M, Pellegrin AO, al. Serologic evidence of the recent circulation of Saint Louis encephalitis virus and high prevalence of equine encephalitis viruses in horses in the Nhecolândia sub-region in South Pantanal, Central-West Brazil. Mem Inst Oswaldo Cruz 2010; 105:829-833.

22. Vasconcelos PF, Da Rosa JF, Da Rosa AP, Dégallier N, Pinheiro FP, Sá Filho GC. Epidemiology of encephalitis caused by arbovirus in the Brazilian Amazonia. Rev Inst Med Trop Sao Paulo 1991; 33:465-476.

23. Maia FG, Chávez JH, Souza WM, Romeiro MF, de Castro LA, da Fonseca BA, et al. Infection with Saint Louis encephalitis virus in the city of Ribeirão Preto, Brazil: report of one case. Int J Infect Dis 2014; 26C:96-97. 